\title{
Outpatient cardiology clinic: future importance of out-of-hospital work-up and treatment in cardiology
}

\author{
(D)Diana Rudan*, \\ (D)Miroslav Raguž, \\ DIvana Jurin, \\ (i) Hrvoje Falak, \\ (DTomislav Svaguša, \\ CDominik Buljan, \\ (D) Jelena Kursar, \\ (DNikša Bušić, \\ DDanijela Grizelj, \\ (1)Mario Udovičić, \\ DIrzal Hadžibegović
}

University Hospital Dubrava, Zagreb, Croatia

RECEIVED:

December 6, 2020

ACCEPTED:

December 18, 2020

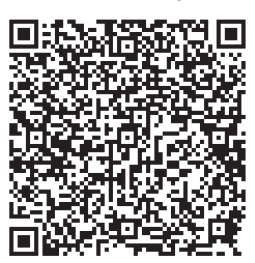

$\square$ Cardiologia Croatica 2021;16(1-2):52.
KEYWORDS: outpatient clinic, imaging, hospitalization, follow-up.

CITATION: Cardiol Croat. 2021;16(1-2):52. | https://doi.org/10.15836/ccar2021.52

*ADDRESS FOR CORRESPONDENCE: Irzal Hadžibegović, Klinička bolnica Dubrava, Avenija Gojka Šuška 6, HR-10000 Zagreb, Croatia. / Phone: +385-91-5333091 / E-mail: irzalh@gmail.com

ORCID: Diana Rudan, https://orcid.org/0000-0001-9473-2517 • Miroslav Raguž, https://orcid.org/0000-0003-1567-8503 Ivana Jurin, https://orcid.org/0000-0002-2637-9691 • Hrvoje Falak, https://orcid.org/0000-0002-6502-683X Tomislav Svaguša, https://orcid.org/0000-0002-2036-1239 • Jelena Kursar, https://orcid.org/0000-0001-8791-4910 Danijela Grizelj, https://orcid.org/0000-0002-8298-7974 • Mario Udovičić, https://orcid.org/0000-0001-9912-2179 Irzal Hadžibegović, https://orcid.org/0000-0002-3768-9134

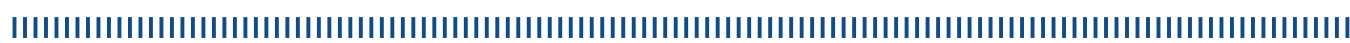

Background: Outpatient non-invasive and invasive diagnostic and therapeutic procedures and outpatient follow-up in cardiology are definitely going to increase in near future. ${ }^{1} \mathrm{Aim}$ : To analyze diagnostic and therapeutic procedures performed within outpatient cardiology clinic in University Hospital Dubrava in 2019 and 2020 and to observe future opportunities and threats.

Methods: We analyzed and compared data on non-invasive and invasive diagnostic and therapeutic procedures performed in outpatient clinic during 2019 (12-month active period including renovation and dislocation period was analyzed) and 2020. (4.5 months active period between the two waves of the COVID-19 pandemic in Croatia was analyzed).

Results: During the 12 months period in 2019 there were 205 coronary angiographies, 30 cardioversions, 146 MSCT coronary and aortic (TAVI assessment) angiographies, 81 LVAD controls, and 325 administered intravenous therapies. In the year 2020. outpatient clinic was closed during the pandemic and reorganization of University Hospital Dubrava as a dedicated COVID-19 hospital. During the 4,5 months active period in 2020 there were 136 coronary angiographies, 18 cardioversions, 192 MSCT coronary and aortic (TAVI assessment) angiographies, 17 LVAD controls, and 186 administered intravenous therapies. During both observed periods there were only 4 documented hospitalizations due to complications after invasive outpatient procedures (1 contrast induced nephropathy, 2 bleeding events and 1 minor vascular complication).

Conclusion: Outpatient non-invasive and invasive diagnostic and therapeutic procedures increased in the period between the two waves of the COVID-19 pandemic, showing the importance of outpatient cardiology clinic in providing needed health care for patients with cardiovascular diseases during and after the pandemic. In future, hospitalization and prolonged hospital stay will most probably be avoided, with growing opportunities for outpatient clinics, but also with growing needs for changing our everyday habits in diagnostic and therapeutic procedures.
LITERATURE IIIIIIIIIIIIIIIIIIIIIIIIIIIIIIIIIIIIIIIIIIIIIIIIIIIIIIIIIIIIIIIIIIIIIIIIIIIIIIIIIIIIIIIIIIIIIIIIIII

1. Wosik J, Clowse MEB, Overton R, Adagarla B, Economou-Zavlanos N, Cavalier J, Henao R, Piccini JP, Thomas L, Pencina MJ, Pagidipati NJ. Impact of the COVID-19 pandemic on patterns of outpatient cardiovascular care. Am Heart J. 2021 Jan;231:1-5. https://doi.org/10.1016/j.ahj.2020.10.074 